\title{
Effect of customer demand information sharing on a four-stage serial supply chain performance: an experimental study
}

\author{
T. Chinna Pamulety ${ }^{\mathrm{a}}$ and V. Madhusudanan Pillai ${ }^{\mathrm{b}^{*}}$
} \author{
C H RON I C L E \\ Article history: \\ Received April 20, 2015 \\ Received in revised format June \\ 10,2015 \\ Accepted September 312015 \\ Available online \\ October 72015 \\ Keywords: \\ Supply chain \\ Bullwhip effect \\ Performance \\ Customer demand information \\ sharing
}

${ }^{a}$ Research Scholar, Department of Mechanical Engineering, National Institute of Technology Calicut, Calicut - 673 601, Kerala, India ${ }^{b}$ Associate Professor, Department of Mechanical Engineering, National Institute of Technology Calicut, Calicut-673 601, Kerala, India

\section{A B S T R A C T}

\begin{abstract}
Customer Demand Information (CDI) sharing plays a vital role in reducing the bullwhip effect as well as in improving the performance of a supply chain. The objective of the present research is to identify the best form of CDI sharing experimentally for a four-stage serial supply chain under lost sales business environment. A supply chain role play game software package is developed for conducting suitable experiments. Different forms of CDI sharing tested in this research are periodic CDI, history of CDI and CDI in the form of distribution. It is found that all forms of CDI sharing have significant impact on the reduction of bullwhip effect compared to non-sharing of information and the upstream stages in the supply chain are benefited the most under CDI sharing. The statistical analysis also confirms that sharing CDI in the form of distribution is the most effective among the various forms of information sharing studied. The percentage reductions in magnitude of order variance under the most benefitted information sharing at distributor and factory stages are 64.43 and 66.04, respectively. It is also found that the performance of a supply chain depends on the degree of customer demand information shared among the stages in the supply chain.
\end{abstract}

\section{Introduction}

"Supply chain consists of all parties involved, directly or indirectly, in fulfilling a customer request" (Chopra et al. 2007). Amplification of demand variability from downstream stage to upstream stage in a supply chain is referred as bullwhip effect (Lee et al., 1997). Forrester (1958) is the first to report on this phenomenon. Bullwhip effect (BWE) has been observed in the commercial operations of many industries and a few of them are: Textile industry (Zymelman, 1965), Hewlett-Packard (HP) (Lee et al., 1997), Procter \& Gamble (P\&G) (Lee et al., 1997), Automotive component supply chain in UK (Taylor, 2000), Machine tool industry (Anderson et al., 2000), Clothing supply chain (Disney \& Towill 2003), Grocery retailer in United Kingdom (Ge et al., 2004), Phillip Electronics (Kok et al., 2005), Semiconductor equipment industry (Terwiesch et al., 2005), Campbell Soup (O'donnell et al., 2006) and Wal-Mart (Bhattacharya \& Bandyopadhyay, 2011). This phenomenon is also termed as 'whip-

* Corresponding author Tel. : 09895367804

E-mail address: vmp@nitc.ac.in (V. Madhusudanan Pillai)

(C) 2016 Growing Science Ltd. All rights reserved. doi: $10.5267 /$ j.uscm.2015.10.001 
lash' or 'whip-saw effect' (Lee et al., 1997) and 'instability problem' (Ouyang \& Li, 2010) by some industries. Generally, increase in variance of orders creates excessive inventories or shortages, poor customer services due to unavailability of products or long backorders, insufficient or excessive capacities, or unstable or uncertain production planning. Thus, the presence of bullwhip effect in a supply chain is costly (Metters, 1997), harmful (Wright \& Yuan, 2008) and decreases the efficiency of the supply chain (Sucky, 2009). Reduction in bullwhip effect showed significant improvement in the profitability of the whole supply chain (Metters, 1997; Caloiero et al., 2008; Bottani et al., 2010).

The causes of the bullwhip effect are: (i) Lack of customer demand information (Sterman, 1989), (ii) Flaws in demand forecast updating, order batching, variation in prices, rationing and shortage gaming (Lee et al., 1997), (iii) Lead time (Chen et al., 2000; Simchi-Levi et al., 2008; Wang et al., 2008), (iv) Replenishment rule (Dejonckheere et al., 2003; Disney \& Towill 2006), (v) Behavioural aspects of managers (Croson \& Donohue, 2006; Nienhaus et al., 2006), (vi) Overestimation (Sucky 2009), (vii) Capacity limit and number of levels in a supply chain (Paik \& Bagchi 2007), and (viii) Free return policies, inflated orders, no communication and no coordination up and down in a supply chain, overreaction to backlogs, and product promotions (Buchmeister et al., 2008).

Lack of customer demand information leads to demand/information distortion as one move from downstream to upstream stages and as a result the requirements at upstream stages are difficult to estimate (Sterman, 1989). So the sharing of Customer Demand Information (CDI), which is the information related with the demand that the retailer faces, can give protection from the uncertainty and is essential for reducing the bullwhip effect (Chen et al., 2000). Different forms of CDI sharing include sharing each period customer demand, history of customer demand and distribution of customer demand. Information regarding future customer demand is called Advance Demand Information (ADI). If it is with certainty, it is perfect ADI otherwise termed as imperfect ADI (Tan et al., 2007). In this study, sharing the distribution of customer demand in advance is called imperfect ADI.

Performance of a supply chain can be investigated by analytical, experimental or simulation methods. Beer distribution game is used to evaluate the performance of a serial supply chain experimentally in which each stage is managed by a human being. The beer distribution game is a simulation of the supply chains with four stages viz. retailer, wholesaler, distributor and factory; the details of which are reported by Sterman (1989 and 2009). The experimental studies reviewed in the present study are given in Table 1. The details such as the structure of supply chain, lead time, demand distribution, business environment, performance measure(s) used and the key findings of each study are summarized in Table 1. There are a good number of reports on the analytical studies in describing the effect of lead time on bullwhip effect. Metters (1997) reported lead time as the overriding cause of bullwhip effect. Long lead time is one of the causes of bullwhip effect (Lee et al., 1997) and it also increases the complexity of decision making (Wu \& Katok, 2006). Bullwhip effect was found high under long lead time (SimchiLevi et al., 2008). Study by Wang et al., (2008) on the impact of lead time on bullwhip effect and total inventory showed that fluctuation in orders are more if the lead time is long, and thus the bullwhip effect is evident. Long lead time in the stages of a supply chain increases the total inventory. Reduction in lead time reduces the bullwhip effect more than the information sharing (Agrawal et al., 2009).

The above literature survey shows that lead time is one of the major causes of bullwhip effect. If the time between order and delivery is large, it can act as a major reason for confusion at the mind of decision maker while placing the order. Order placed at one point, generally, meets the demand of some distant future period(s). So, lead time can contribute considerably to variation in orders. Similarly, backorders are a major contributor of variation in order sizes. Due to backorders, the replenishment quantity varies considerably and as a result the order placed may also vary. Most of the previous researchers in their experimental studies have considered long lead time (4 periods) and uniform distribution with a range of 0 to 8 or step-up demand pattern for the customer demand (Sterman, 1989; Croson \& Donohue, 2003, Croson \& Donohue, 2006, Wu \& Katok, 2006); assuming a uniform 
customer demand is unusual (Steckel et al., 2004) and normal distribution is the best choice for the same (Chan \& Chan, 2010).

\section{Table 1}

Experimental studies reviewed in the present study

\begin{tabular}{|c|c|c|c|c|c|c|c|}
\hline $\begin{array}{l}\text { Author } \\
\text { and year }\end{array}$ & $\begin{array}{c}\text { Type of } \\
\text { information } \\
\text { sharing }\end{array}$ & $\begin{array}{l}\text { Performance } \\
\text { measure used }\end{array}$ & $\begin{array}{l}\text { Customer } \\
\text { Demand }\end{array}$ & Lead time & $\begin{array}{c}\text { Business } \\
\text { environment }\end{array}$ & $\begin{array}{l}\text { Supply } \\
\text { chain }\end{array}$ & Key results \\
\hline $\begin{array}{l}\text { Sterman } \\
(1989)\end{array}$ & - No sharing & $\begin{array}{l}\text { BWE, Total } \\
\text { Cost of the } \\
\text { Supply Chain } \\
\text { (TCSC) }\end{array}$ & Step-up & $\begin{array}{l}\text { Four weeks } \\
\text { for retailer, } \\
\text { wholesaler } \\
\text { and } \\
\text { distributor } \\
\text { Three } \\
\text { weeks for } \\
\text { factory }\end{array}$ & Backorder & $\begin{array}{l}\text { Four- } \\
\text { stage } \\
\text { serial }\end{array}$ & $\begin{array}{l}\text { - Misperception in } \\
\text { feedback leads to } \\
\text { BWE } \\
\text { - Large variation in } \\
\text { orders is due to lack } \\
\text { of customer demand } \\
\text { information }\end{array}$ \\
\hline $\begin{array}{l}\text { Croson } \\
\text { and } \\
\text { Donohue } \\
(2003)\end{array}$ & $\begin{array}{l}\text { - Imperfect ADI } \\
\text { - Point of Sale } \\
\text { (PoS) with } \\
\text { imperfect ADI }\end{array}$ & BWE & $\mathrm{U}(0,8)$ & $\begin{array}{l}\text { - Same as in } \\
\text { Sterman } \\
(1989)\end{array}$ & Backorder & $\begin{array}{l}\text { Four- } \\
\text { stage } \\
\text { serial }\end{array}$ & $\begin{array}{l}\text { PoS with imperfect } \\
\text { ADI was not shown } \\
\text { significant impact on } \\
\text { BWE than imperfect } \\
\text { ADI sharing }\end{array}$ \\
\hline $\begin{array}{l}\text { Steckel } \\
\text { et al. } \\
(2004)\end{array}$ & - $\mathrm{PoS}$ & TCSC & $\begin{array}{l}\text { - Step-up } \\
\text { - S-shaped with } \\
\text { stationary } \\
\text { disturbances } \\
\text { - Errorless S- } \\
\text { shaped pattern }\end{array}$ & $\begin{array}{l}\text { - Under four } \\
\text { weeks and } \\
\text { two weeks }\end{array}$ & Backorder & $\begin{array}{l}\text { Three- } \\
\text { stage } \\
\text { serial }\end{array}$ & $\begin{array}{l}\text { Reduction in lead } \\
\text { time more beneficial } \\
\text { than sharing PoS data }\end{array}$ \\
\hline $\begin{array}{l}\text { Croson } \\
\text { and } \\
\text { Donohue } \\
(2005 \mathrm{a})\end{array}$ & $\begin{array}{l}\text { - No information } \\
\text { - Downstream } \\
\text { inventory } \\
\text { - Upstream } \\
\text { inventory }\end{array}$ & BWE & $\mathrm{U}(0,8)$ & $\begin{array}{l}\text { - Same as in } \\
\text { Sterman } \\
(1989)\end{array}$ & Backorder & $\begin{array}{l}\text { Four- } \\
\text { stage } \\
\text { serial }\end{array}$ & $\begin{array}{l}\text { - Impact of } \\
\text { downstream } \\
\text { inventory information } \\
\text { sharing is significant }\end{array}$ \\
\hline $\begin{array}{l}\text { Croson et } \\
\text { al. (2014) }\end{array}$ & $\begin{array}{l}\text { - Coordination } \\
\text { stock } \\
\text { - Common } \\
\text { knowledge }\end{array}$ & $\begin{array}{l}\text { BWE and } \\
\text { TCSC }\end{array}$ & $\begin{array}{l}\text { Constant demand } \\
\text { of } 4 \text { units per } \\
\text { week }\end{array}$ & $\begin{array}{l}\text { - Same as in } \\
\text { Sterman } \\
(1989)\end{array}$ & Backorder & $\begin{array}{l}\text { Four- } \\
\text { stage } \\
\text { serial }\end{array}$ & $\begin{array}{l}\text { - Coordination risk is } \\
\text { another behavioural } \\
\text { cause of bullwhip } \\
\text { effect }\end{array}$ \\
\hline $\begin{array}{l}\text { Croson } \\
\text { and } \\
\text { Donohue } \\
(2006)\end{array}$ & $\begin{array}{l}\text { - Imperfect ADI } \\
\text { - Inventory } \\
\text { information }\end{array}$ & BWE & $\mathrm{U}(0,8)$ & $\begin{array}{l}\text { - Same as in } \\
\text { Sterman } \\
(1989)\end{array}$ & Backorder & $\begin{array}{l}\text { Four- } \\
\text { stage } \\
\text { serial }\end{array}$ & $\begin{array}{l}\text { - Inventory } \\
\text { information sharing } \\
\text { significantly reduced } \\
\text { the BWE }\end{array}$ \\
\hline $\begin{array}{l}\text { Wu and } \\
\text { Katok } \\
(2006)\end{array}$ & $\begin{array}{l}\text { Learning, } \\
\text { training and } \\
\text { communication }\end{array}$ & BWE & $\mathrm{U}(0,8)$ & $\begin{array}{l}\text { - Same as in } \\
\text { Sterman } \\
(1989)\end{array}$ & Backorder & $\begin{array}{l}\text { Four- } \\
\text { stage } \\
\text { serial }\end{array}$ & $\begin{array}{l}\text { - Training and } \\
\text { communication } \\
\text { significantly reduced } \\
\text { the BWE }\end{array}$ \\
\hline $\begin{array}{l}\text { Nienhaus } \\
\text { et al. } \\
(2006)\end{array}$ & $\begin{array}{l}\text { - Information } \\
\text { sharing (stock } \\
\text { in all stages and } \\
\text { allowed to chat } \\
\text { with players) } \\
\text { - Non-sharing of } \\
\text { information } \\
\text { - Agent based } \\
\text { strategy }\end{array}$ & TCSC & Step-up & $\begin{array}{l}\text { - Three } \\
\text { weeks }\end{array}$ & Backorder & $\begin{array}{l}\text { Four- } \\
\text { stage } \\
\text { serial }\end{array}$ & $\begin{array}{l}\text { - Information sharing } \\
\text { improves the } \\
\text { performance of the } \\
\text { supply chain } \\
\text { - Safe-harbour and } \\
\text { panic strategy of } \\
\text { human players are the } \\
\text { causes of BWE }\end{array}$ \\
\hline $\begin{array}{l}\text { Cantor } \\
\text { and } \\
\text { Katok } \\
(2012)\end{array}$ & - Imperfect ADI & BWE & $\mathrm{U}(0,8)$ & $\begin{array}{l}\text { Two weeks } \\
\text { for retailer, } \\
\text { one-week } \\
\text { for factory }\end{array}$ & Backorder & $\begin{array}{l}\text { Two- } \\
\text { stage } \\
\text { serial }\end{array}$ & $\begin{array}{l}\text { - Simplifying the } \\
\text { structure of the } \\
\text { supply chain leads to } \\
\text { production smoothing }\end{array}$ \\
\hline
\end{tabular}

Carter et al. (2007), Bendoly et al. (2010), Tokar (2010), and Cantor and Katok (2012) highlighted the need for behavioural research in logistics and supply chain management in which human beings are used for conducting experiments. They concluded that the behavioural research in logistics and supply chain management can significantly advance both theory and practice in the logistics and supply chain management. Hence, the authors of this paper are motivated to evaluate the performance of supply chain by conducting the experiments using human beings at a small lead time of one period under lost sales business environment. This experimental work is different from the research works reported in the literature in terms of lead time, demand distribution and its magnitude and variability, and business environment. One of the objectives of this work is to test the presence of bullwhip effect experimentally under CDI sharing in a small lead time (one period) and no backorders environment. No backorders 
are assumed because customers do not wish to wait for their needs in the present competitive world and backorder is also one of the causes of the bullwhip effect (Pillai \& Pamulety, 2013). The second objective is to measure the performance of the supply chain using various performance measures viz. variance of orders placed by each stage, total inventory at each stage and total inventory of the supply chain. The third objective is to identify the most effective type of CDI sharing. Here, three types of information sharing are considered such as: (i) periodic CDI (ii) history of CDI (iii) CDI in the form of a distribution. Further, the study is aimed to identify the benefitted stages in the supply chain under different forms of CDI sharing. Suitable hypothesis are formulated for testing the above objectives.

This paper is organized as follows: Features of supply chain role play game software package developed are discussed in Section 2. Section 3 gives the details of experimental settings in the package for the present study. Assumptions and experimental procedure are described in Section 4. Results are given in Section 5 and Statistical tests conducted are explained in Section 6. Section 7 provides discussion and conclusions of the study are given in Section 8.

\section{Features of supply chain role play game software package developed}

Generally, Beer distribution game is used for evaluating the performance of a supply chain experimentally under backorder cases. For meeting the objectives of present study, flexibility in setting the parameters of a supply chain is required and thus a customized supply chain role play game software package is developed. The details and features of this package are explained below. The suitability of the software package for experiments in supply chain management is analysed and validated with the results available in the literature and are available in Pillai and Pamulety (2013).

In a four-stage serial supply chain, four participants are required to form a team or a supply chain and each participant acts as manager of a stage. The four stages in the supply chain are retailer, wholesaler, distributor and factory. This game is played in networked computers where each participant has a client computer and manages his/her role in the supply chain. A maximum of 10 teams can participate in the role play at a time. An instructor or admin set the parameters of the supply chain and assign roles to each participant. Various parameters of the supply chain to be set are: (i) number of supply chains (In the package, it is given as number of games), (ii) type of information sharing between the stages (game type), (iii) customer demand (The package has demand generators following normal or uniform distributions. Desired demand data manually also can be set in the package.), (iv) maximum number of periods for the game play, (v) time required to reach the order from lower stage to the next higher stage (order lead time), (vi) time required for the shipment quantity to reach the immediate downstream stage (delivery lead time), (vii) initial inventory, (viii) performance evaluation period and (ix) holding cost per unit per period at each stage. The screenshot showing the interfaces for setting the above parameters are given in Fig. 1 and Fig. 2.

This web based software package uses Hyper Text Markup Language (HTML), Cascading Style Sheets (CSS) and Java Script and MySQL. HTML, CSS and Java Script are used as front-end for this software and MySQL is used as back-end.

After setting the parameters, participants can login into the respective supply chain stage with password generated by the software package. Retailer places order to wholesaler, wholesaler to distributor, distributor to factory and factory issues production orders. A retailer stage window at week 1 is shown in Fig. 3 which contains periodic details such as (i) customer order (demand), (ii) backorder quantity (this quantity has significance, if the game is played under backorder environment), (iii) Retailer inventory (on-hand inventory), (iv) replenishment quantity and (v) outstanding orders which will be useful for taking decision on the size of order to be placed. The order decision is recorded along with inventory status for each period. This play run for several periods and the recorded data is used to evaluate the performance of the supply chain. 


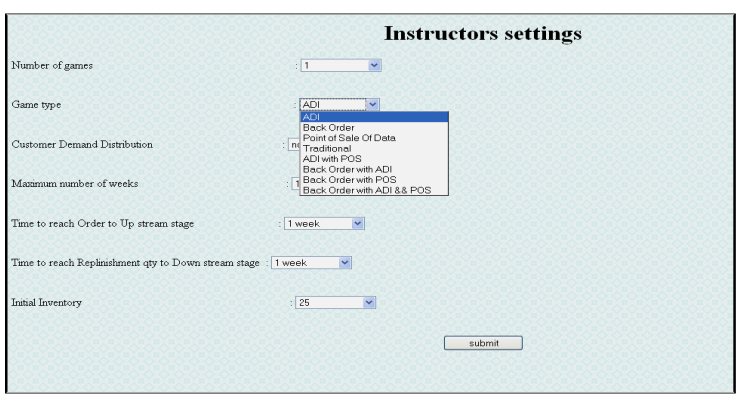

Fig.1. Interface for setting the supply chain parameters - page 1

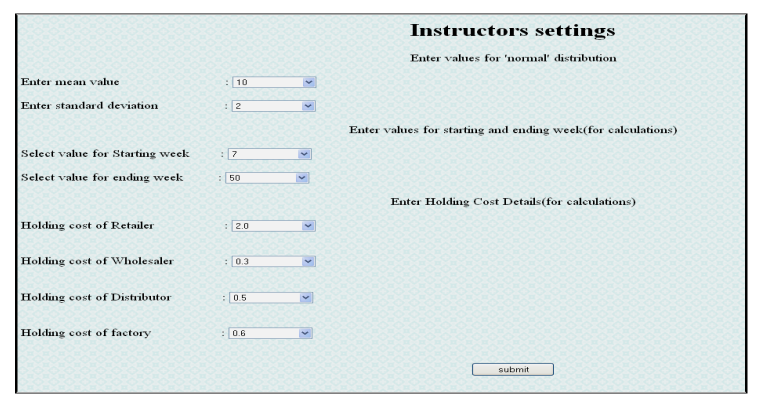

Fig. 2. Interface for setting the supply chain parameters - page 2

\section{Details of experimental settings in the package for the present study}

In this study, the experiments are conducted by setting the supply chain under different information sharing settings such as: (i) non-sharing information, (ii) sharing periodic CDI, (iii) sharing history of $\mathrm{CDI}$ and (iv) sharing imperfect ADI. The screenshot of a retailer stage under non-sharing of information setting is shown in Fig. 3 and screenshot for other information sharing settings of a wholesaler stage are provided in Fig. 4, Fig. 5 and Fig. 6 respectively. The initial parameter setting such as order lead time, delivery lead time, customer demand distribution, initial inventory, etc. is the same for all experiments but the type of CDI shared differs.

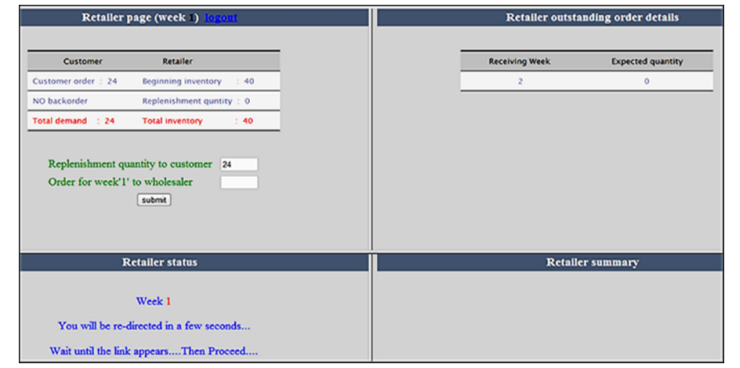

Fig. 3. Screenshot of a retailer stage of a supply chain (nonsharing of information setting)

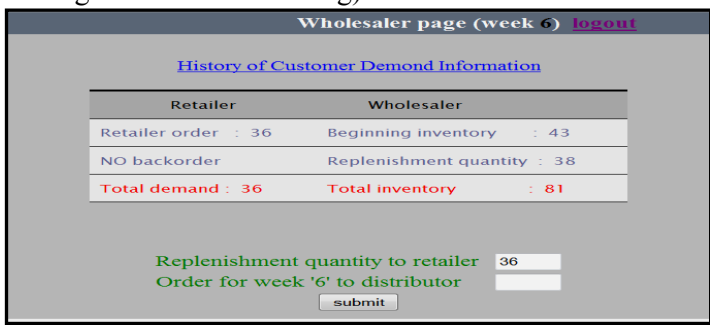

Fig. 5. History of customer demand information sharing

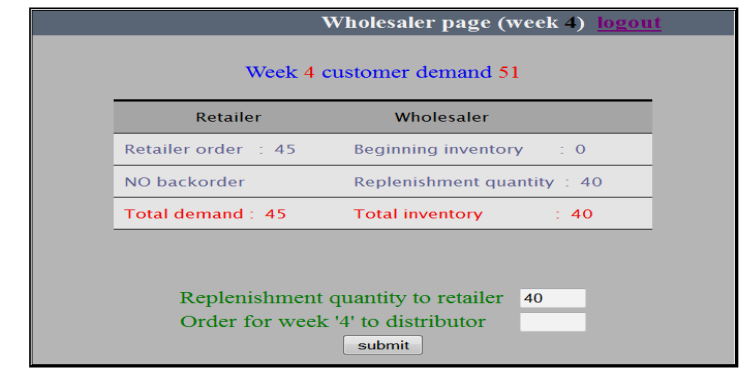

Fig. 4. Customer demand per period sharing

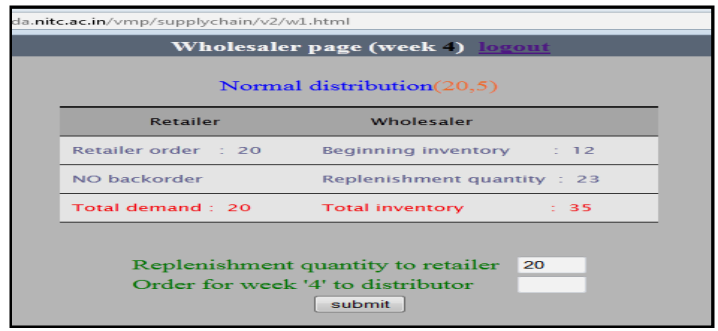

Fig. 6. Imperfect advance demand information sharing

The interaction between two consecutive stages is in terms of orders placed under non-sharing of information whereas in all other settings appropriate CDI is shared in addition to order information (see Figs. $4-6$ ). Customer demand occurred at the retailer at each period is shared with all other stages in the periodic CDI setting. Customer demand at the retailer is tabulated and is updated at each period which is shared with all other stages in the history of CDI sharing. The shared information is updated and is displayed at each period in the above information sharing settings. The name and parameters of customer demand distribution is shared in the imperfect ADI setting experiment. The shared information can be used for taking the decision on order size. The CDI was shared instead of Point of Sale (PoS) as the PoS may contain only the demand met from stock. (When the experiment is conducted under lost sales, where demand is greater than inventory, the PoS cannot represent the actual customer demand). In the e-commerce market, it is possible to obtain CDI easily. Under each setting, 9 supply chains are evaluated and 144 members participated in this experimental study. These members are 
under-graduate and post-graduate students, and research scholars of Industrial Engineering and Management specialization.

\section{Assumptions and experimental procedure}

The following assumptions and procedure are applicable to all supply chains ( 9 supply chains in each experimental setting). Customer demand for a single product is generated randomly at each period which follows normal distribution, $\mathrm{N}(20,5)$. When the retailer receives customer order, a decision regarding the size of the order to be placed to its next higher level is taken. It is assumed that the order decision at a stage is made at the end of a period as this decision is taken after shipping the demand quantity for the period. The order size decision is taken with the objective of meeting the demand and minimizing the inventory. At any stage the shipment quantity to its downstream is based on the availability of stock. Similar type of decision is taken in every period at each stage but, the factory stage issues the production order based on the order received and on-hand inventory. The order placed by a stage $(i=1,2,3)$ at the end of time period $t$ reaches its supplier at the beginning of period $(t+1)$ and the shipment made by supplier at the beginning of $(t+1)$ reaches its customer at the beginning of $(t+2)$. It is assumed that the factory $(i=4)$ has unlimited production capacity and resources for production. Hence, the production quantity against the production order issued by factory at the end of period $t$ is available with the factory for distribution at the beginning of $(t+1)$. Fig. 7 shows the shipment and order flows in a serial supply chain.

At each stage, a period begins with the arrival of shipment from its upstream stage and then receives orders from its downstream stage. Initial inventory at each stage is set so that it could satisfy the demand expected till it receives first replenishment order from its supplier. Initial inventory at each stage in the supply chain at the beginning of the game is 40 units. The orders received are met from the available inventory and the remaining inventory is carried over to the next period. The quantity that is not met is considered as lost sales. A period ends when each participant places an order with his/her upstream stage. The duration of the experiment was not revealed to the participants and it was conducted for 55 periods. The data from period 7 to 48 are considered for performance evaluation as in Steckel et al. (2004). The supply chain parameters under which the experiments conducted are given in Table 2 . The performance measures considered in this study are variance of orders (BWE), total inventory at each stage and Total Inventory of the Supply Chain (TISC). TISC is the sum of the inventory at all stages of the supply chain. The variance of orders, total inventory at each stage and the TISC are calculated by the software package using the equation 1,2 and 3, respectively. Notations used in the equations are given below.

\section{Notations:}

$i \quad-$ Stage index in a supply chain, $i=1,2,3,4$

$g \quad-$ Supply chain index, $g=1,2, \ldots, 9$

$t \quad-$ Time period

$n \quad-$ Number of time periods

$S Q_{t}^{i, g}$ - Quantity shipped by stage $i$ of supply chain $g$ in period $t$

$D_{t} \quad-$ Customer demand in period $t$

$O_{t}^{i, g} \quad$ - Order quantity of stage $i$ of supply chain $g$ in period $t$

$\bar{O}_{g} \quad$ - Estimate of average demand per period of supply chain $g$

$\sigma_{i, g} \quad$ - Estimate of variance of orders placed by stage $i$ in supply chain $g$

$P O_{t}^{g}$ - Production order by factory of supply chain $g$ in period $t$

$I_{t}^{i, g} \quad$ - Ending inventory of stage $i$ of supply chain $g$ in period $t$

TISC $^{g}$ - Total inventory of supply chain $g$ 
Initial status of supply chains:

$S Q_{0}^{i, g}=0, \forall i, g ; I_{0}^{i, g}=40, \forall i, g ; O_{0}^{i, g}=0, \forall i, g$

Variance of orders placed by stage, $i, \sigma_{i, g}^{2}=\frac{\sum_{t=7}^{48}\left(O_{t}^{i, g}-\bar{O}\right)^{2}}{n-1}$,

where, $\overline{O_{g}}=\sum_{t=7}^{48} O_{t}^{i, g} / n \quad$ and $n=42$.

Total inventory at each stage $i, I^{i, g}=\sum_{t=7}^{48} I_{t}^{i, g}$

$\operatorname{TISC}^{g}=\sum_{i=1}^{4} \sum_{t=7}^{48} I_{t}^{i, g}$

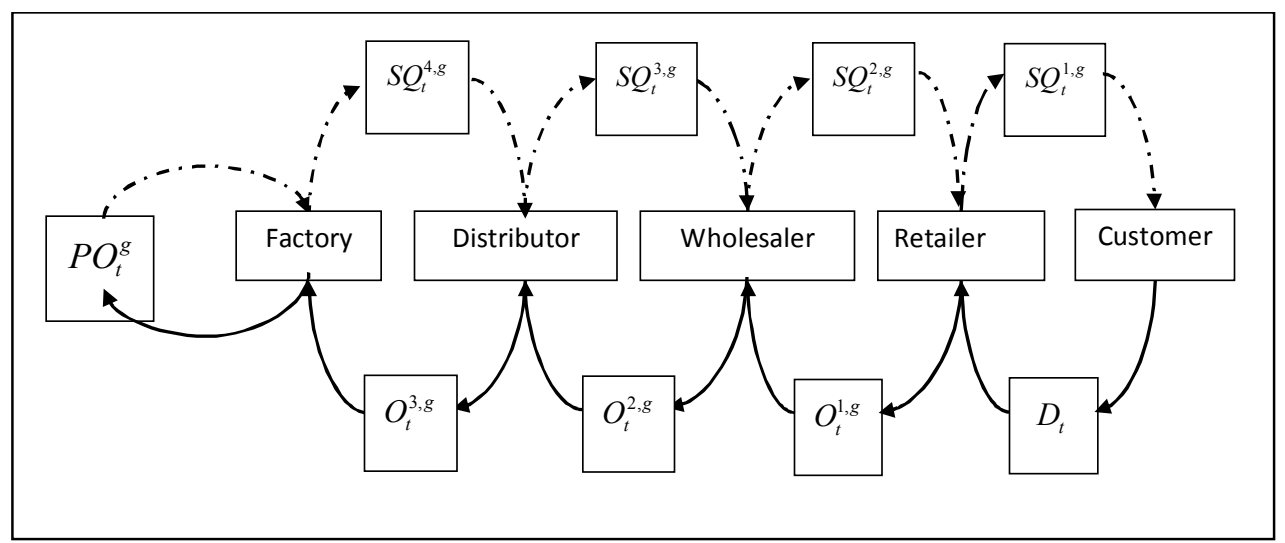

Fig. 7. Order and shipment flows in a serial supply chain.

Table 2

General parameters and stage wise parameter

\begin{tabular}{|c|c|c|c|c|}
\hline \multicolumn{5}{|c|}{ General parameters } \\
\hline \multicolumn{3}{|c|}{ Customer demand distribution } & & $\mathrm{N}(20,5)$ \\
\hline \multicolumn{3}{|c|}{ Duration of the play } & & 55 periods \\
\hline \multicolumn{3}{|c|}{ Performance evaluation period } & & 7 to 48 \\
\hline \multicolumn{5}{|c|}{ Stage wise parameters } \\
\hline Stage & Initial inventory & Holding cost (\$) & Order lead time & Delivery lead time \\
\hline Retailer & 40 units & 0.5 & 0 & 1 period \\
\hline Wholesaler & 40 units & 0.5 & 0 & 1 period \\
\hline Distributor & 40 units & 0.5 & 0 & 1 period \\
\hline Factory & 40 units & 0.5 & 0 & 0 \\
\hline
\end{tabular}

\section{Results}

The performance measures are calculated for each supply chain and the average value of each performance measure over nine supply chains in each setting is shown in Fig.s 8 - 10. The average value of variance of orders placed by each stage, total inventory at each stage and the TISC under different settings are shown in Fig. 8, Fig. 9 and Fig. 10, respectively. Fig. 8 shows that the average value of variance of orders at each stage is less under CDI sharing experiments than non-sharing information settings. The TISC under imperfect ADI sharing is less compared to other settings from Fig. 10. The effect of different forms of CDI sharing on variance of orders (BWE) placed by each stage 
is shown in Fig. 11. It is also observed that the variance of orders placed by each stage is less under imperfect ADI sharing than other forms of CDI sharing.

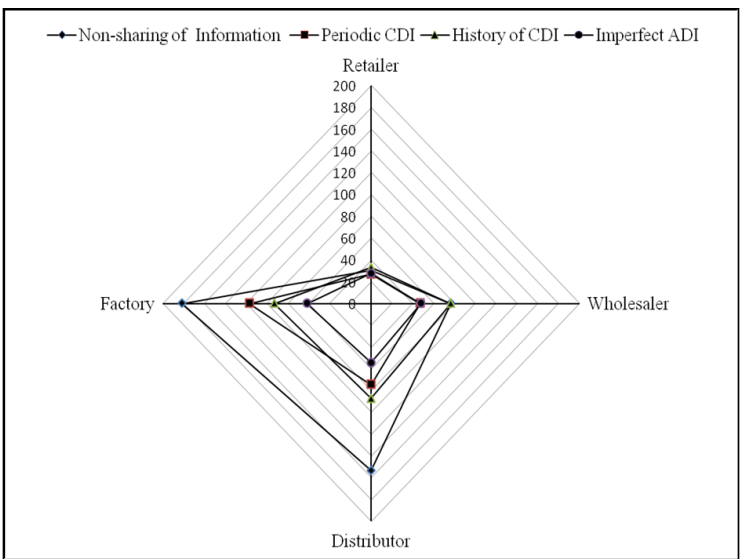

Fig. 8. Average value of variance of orders at each stage under different information sharing settings

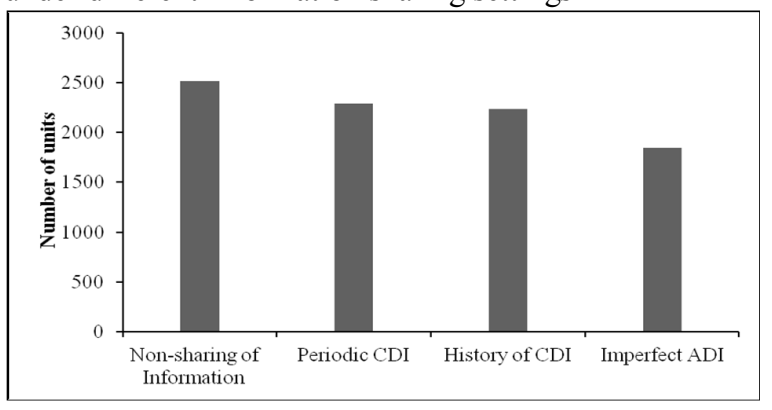

Fig. 10. Average value of TISC under different information sharing settings

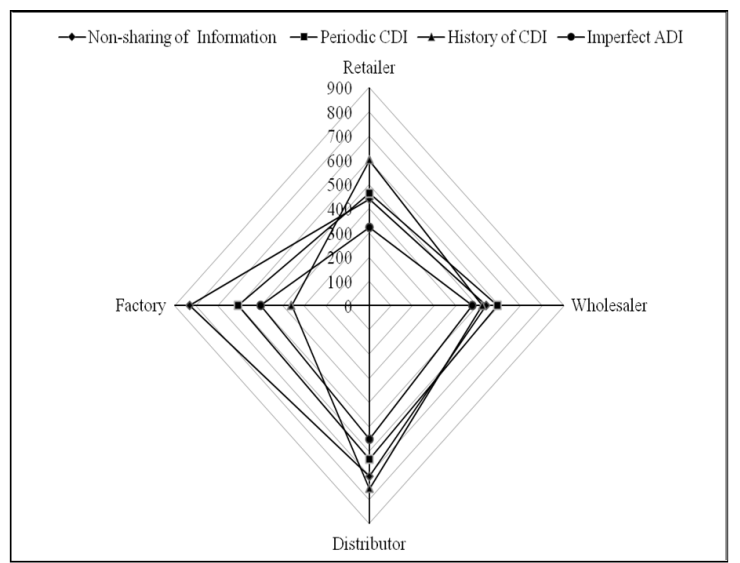

Fig. 9. Average value of inventory at each stage under different information sharing settings

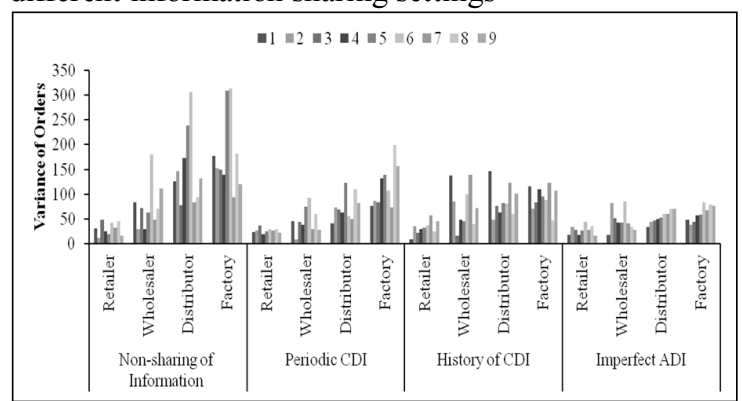

Fig. 11. Impact of different forms of CDI sharing on BWE

\section{Statistical tests conducted}

Various statistical tests are conducted to draw conclusions on the impact of different forms of CDI sharing on the performance of the serial supply chains. Sign test is used to know the presence of bullwhip effect in the supply chain under various CDI sharing settings. Wilcoxon-Mann-Whitney test (also known as Wilcoxon test) is used to know the impact of various forms of CDI sharing on the variance of orders in the supply chain and on each stage of the supply chain. All the statistical tests are evaluated at $5 \%$ significance level and one-sided $p$-values are reported for the test results. Results found to be significant are highlighted in the respective tables.

\subsection{Test for the presence of bullwhip effect}

To test the presence of bullwhip effect under each form of CDI sharing with small lead time (one period) and no backorders, the hypotheses formulated are as follows:

Hypothesis-H1: Bullwhip effect will not occur under periodic CDI sharing with small lead time and no backorders.

Hypothesis-H2: Bullwhip effect will not occur under history of CDI sharing with small lead time and no backorders.

Hypothesis-H3: Bullwhip effect will not occur under imperfect ADI with small lead time and no backorders.

Sign test, a non-parametric statistical test, is used to test the presence of bullwhip effect in a supply chain (Croson \& Donohue 2006; Wu \& Katok 2006). In this test, for each supply chain, an increase in variance of orders between two consecutive stages is coded as a success and a decrease is coded as a 
failure. Success is represented by a plus $(+)$ sign and a failure is represented by a minus $(-)$ sign. The probability of occurrence of failure or success is equal and is 0.5. It is coded as zero, if there is no change in variance of orders and is dropped from the analysis. The sum of the plus and the minus signs is considered as sample size $(\mathrm{N})$. If the sum of plus signs is represented by ' $\mathrm{X}$ ', then the probability of getting ' $\mathrm{X}$ ' or more plus signs is calculated using the Binomial distribution. If this probability is less than the significance level fixed, then the hypothesis must be rejected. The above procedure is followed for testing the presence of bullwhip effect in each form of CDI sharing and the details are given in Table 3.

Table 3

Test for the presence of bullwhip effect under different supply chain settings

\begin{tabular}{rlcrcc}
\hline S1. & \multirow{2}{*}{ Hypothesis } & Success rate (\%) & \multicolumn{3}{c}{ Sign test parameters } \\
\cline { 4 - 6 } No. & & & $N$ & $X$ & $p$ \\
\hline 1 & H1:Periodic CDI & 88.88 & 27 & 24 & $\mathbf{0 . 0 0 0 0}$ \\
2 & H2:History of CDI & 77.77 & 27 & 21 & $\mathbf{0 . 0 0 2 9}$ \\
3 & H3:Imperfect ADI & 74.07 & 27 & 20 & $\mathbf{0 . 0 0 9 5}$ \\
\hline
\end{tabular}

From Table 3, it is found that the $p$-value of all information sharing settings is less than the significance level and hence the success rate is higher than the chance rate of $50 \%$. Thus, the hypothesis framed should be rejected. Hence, the study concludes that the bullwhip effect occurs in supply chain under all forms of CDI sharing.

\subsection{The impact of information sharing on the magnitude of variance of orders}

Wilcoxon-Mann-Whitney test (Siegel \& Castellan 1988) is used to know the impact of different forms of customer demand information sharing on the magnitude of variance of orders (Croson \& Donohue 2003; Steckel et al., 2004; Croson \& Donohue 2006). The impact of a particular form of CDI sharing on variance of orders is known by comparing it with the variance of orders under non-sharing of information. This test considers the variance of orders placed by all stages under one set of experiment as one group, say $x$, and the variance of orders placed by all stages in another set of experiment as another group, say $y$. Let the number of observations in group $x$ and $y$ are $l$ and $m$, respectively. In this test, the observations of both the groups are combined and the rank for each observation is assigned by arranging them in ascending order starting from one to $(l+m)$. If observations are equal, average rank is assigned to both observations. If there is a significant difference between the two groups, then most of the high ranks will belongs to one group and most of the low ranks will belongs to other one. As a result, the sum of the ranks belonging to each group is quite different. On the other hand, if the two groups are similar, then the high and low ranks are distributed fairly even between the two groups and the sum of the ranks belongs to each group are more or less same. After assigning ranks, the statistics $W_{x}, W_{y}$, and $z$ (if $l$ or $m$ greater than 10) are calculated. $W_{x}$ and $W_{y}$ are the sum of the rank of observations belonging to the groups $x$ and $y$ respectively.

$$
z=\frac{W_{x} \pm 0.5-\mu_{W_{x}}}{\sigma_{w_{x}}}
$$

where, Mean $=\mu_{W_{x}}=\frac{l(K+1)}{2} ;$ Variance $=\sigma_{W_{x}}^{2}=\frac{\operatorname{lm}(K+1)}{12}$;

$$
K=l+m
$$

The null hypothesis is that the variance of orders is equal in the supply chain under two different settings. This hypothesis needs to be rejected when the probability value for the calculated $z$ value is less than the fixed significance level $\alpha$. If the number of observations in any group $(l$ or $m)$ is less than 10 , the probability associated with the occurrence under null hypothesis of any $W_{x}$ as extreme as the observed value is determined and the null hypothesis must be rejected, if this probability is less than 
the fixed significance level $\alpha$. The hypothesis framed under different settings is given below and are tested by following the above procedure. The details of the test and results are given in Table 4 .

Hypothesis-H4: Variance of orders in the stages of supply chain under non-sharing of information and under periodic CDI sharing is equal.

Hypothesis-H5: Variance of orders in the stages of supply chain under non-sharing of information and under history of CDI sharing is equal.

Hypothesis-H6: Variance of orders in the stages of supply chain under non-sharing of information and under imperfect ADI sharing is equal.

\section{Table 4}

Test for the impact of information sharing on magnitude of variance of orders

\begin{tabular}{clcccc}
\hline Sl. & \multirow{2}{*}{ Hypothesis } & \multicolumn{3}{c}{ Wilcoxon Parameters } \\
\cline { 3 - 6 } No. & & $W_{x}$ & $W_{y}$ & $z$ & $p$ \\
\hline 1 & H4: Non-sharing of information Vs Periodic CDI & 1517 & 1111 & 2.29 & $\mathbf{0 . 0 1 1 0}$ \\
2 & H5: Non-sharing of information Vs History of CDI & 1461 & 1167 & 1.66 & $\mathbf{0 . 0 4 8 5}$ \\
3 & H6: Non-sharing of information Vs Imperfect ADI & 1619 & 1009 & 3.44 & $\mathbf{0 . 0 0 0 3}$ \\
\hline
\end{tabular}

Since the $p$-value of all the above tests is less than the significance level fixed, the hypothesis framed under these settings must be rejected. Hence, it is inferred that the variance of orders in a supply chain is significantly less under different forms of CDI sharing compared to non-sharing information. Further analysis is carried out by conducting a similar test to know the best form of CDI sharing and results are given in Table 5. The hypotheses are the following:

Hypothesis-H7: Variance of orders in the stages of supply chain under periodic CDI sharing and under history of CDI sharing is equal.

Hypothesis-H8: Variance of orders in the stages of supply chain under periodic CDI sharing and under imperfect ADI sharing is equal.

Hypothesis-H9: Variance of orders in the stages of supply chain under history of CDI sharing and under imperfect ADI sharing is equal.

Table 5

Test for identifying the best type of CDI sharing.

\begin{tabular}{cccccc}
\hline Sl. & \multicolumn{2}{c}{ Hypothesis } & \multicolumn{3}{c}{ Wilcoxon Parameters } \\
\cline { 3 - 6 } No. & & $W_{x}$ & $W_{y}$ & $z$ & $p$ \\
\hline 1 & H7:Periodic CDI Vs History of CDI & 1406 & 1222 & 1.04 & 0.1492 \\
2 & H8:Periodic CDI Vs Imperfect ADI & 1439 & 1189 & 1.41 & $\mathbf{0 . 0 7 9 3}$ \\
3 & H9:History of CDI Vs Imperfect ADI & 1565 & 1063 & 2.83 & $\mathbf{0 . 0 0 2 3}$ \\
\hline
\end{tabular}

From Table 5, it is found that the magnitude of variance of orders under imperfect ADI sharing is significantly less than the other CDI sharing types (with $10 \%$ significance level) and there is no statistical evidence for the difference in variance of orders in supply chain under periodic CDI and history of CDI. Thus, the imperfect ADI sharing is the best among the CDI types.

\subsection{Impact of information sharing on variance of orders of each stage}

Wilcoxon test is conducted to know the impact of different forms of customer demand information sharing on the variance of orders at each stage. Since the experiments are conducted under three forms of CDI sharing, the variance of orders at each stage is compared with the variance of orders under nonsharing of information in-order to know the impact of CDI sharing. Hence there are three hypotheses framed and tested for each stage. In this test, the groups $x$ and $y$ are the variance of orders of a stage under two different settings of the supply chain. The hypotheses framed are as follows: 
For retailer stage:

Hypothesis-H10: Variance of orders placed by retailer under non-sharing of information and under periodic CDI sharing is equal.

Hypothesis-H11: Variance of orders placed by retailer under non-sharing of information and under history of CDI sharing is equal.

Hypothesis-H12: Variance of orders placed by retailer under non-sharing of information and under imperfect ADI sharing is equal.

For wholesaler stage:

Hypothesis-H13: Variance of orders placed by wholesaler under non-sharing of information and under periodic CDI sharing is equal.

Hypothesis-H14: Variance of orders placed by wholesaler under non-sharing of information and under history of CDI sharing is equal.

Hypothesis-H15: Variance of orders placed by wholesaler under non-sharing of information and under imperfect ADI sharing is equal.

\section{For distributor stage:}

Hypothesis-H16: Variance of orders placed by distributor under non-sharing of information and under periodic CDI sharing is equal.

Hypothesis-H17: Variance of orders placed by distributor under non-sharing of information and under history of CDI sharing is equal.

Hypothesis-H18: Variance of orders placed by distributor under non-sharing of information and under imperfect ADI sharing is equal.

For factory stage:

Hypothesis-H19: Variance of orders placed by factory under non-sharing of information and under periodic CDI sharing is equal.

Hypothesis-H20: Variance of orders placed by factory under non-sharing of information and under history of CDI sharing is equal.

Hypothesis-H21: Variance of orders placed by factory under non-sharing of information and under imperfect ADI sharing is equal.

The hypotheses framed are tested and parameters of the tests are listed in Table 6. From Table 6, it is evident that the CDI sharing of any form is not having significant impact on the variance of orders of downstream stages such as retailer and wholesaler. But, there is a significant reduction in the upstream stages such as distributor and factory. Since the information sharing is having significant impact at upstream stages, tests are conducted to know which type of information sharing is having highest impact at upstream stages (see Table 7) and it is found that the imperfect ADI is having the significant impact over the other types. The imperfect ADI is, thus, the better form of CDI than the other forms tested in this study. The following are the hypotheses framed.

For distributor stage:

Hypothesis-H22: Variance of orders placed by distributor under periodic CDI sharing and under history of CDI sharing is equal.

Hypothesis-H23: Variance of orders placed by distributor under periodic CDI sharing and under imperfect ADI sharing is equal.

Hypothesis-H24: Variance of orders placed by distributor under history of CDI sharing and under imperfect ADI sharing is equal.

For factory stage:

Hypothesis-H25: Variance of orders placed by factory under periodic CDI sharing and under history of CDI sharing is equal.

Hypothesis-H26: Variance of orders placed by factory under periodic CDI sharing and under imperfect ADI sharing is equal. 
Hypothesis-H27: Variance of orders placed by factory under history of CDI sharing and under imperfect ADI sharing is equal.

Table 6

Test of variance of orders: stage-wise hypothesis and Wilcoxon parameters

\begin{tabular}{|c|c|c|c|c|c|}
\hline \multirow{2}{*}{$\begin{array}{l}\text { Sl. } \\
\text { No. }\end{array}$} & \multirow{2}{*}{ Hypothesis } & \multicolumn{4}{|c|}{ Wilcoxon Parameters } \\
\hline & & $W_{x}$ & $W_{y}$ & & $p$ \\
\hline \multicolumn{6}{|c|}{ Retailer } \\
\hline 1 & H10:Non-sharing of information Vs Periodic CDI & 91 & 80 & $P\left(W_{x} \geq 91\right)$ & 0.3332 \\
\hline 2 & H11:Non-sharing of information Vs History of CDI & 81 & 90 & $P\left(W_{x} \geq 81\right)$ & 0.6668 \\
\hline 3 & H12:Non-sharing of information Vs Imperfect ADI & 90 & 81 & $P\left(W_{x} \geq 90\right)$ & 0.3652 \\
\hline \multicolumn{6}{|c|}{ Wholesaler } \\
\hline 4 & H13:Non-sharing of information Vs Periodic CDI & 103 & 68 & $P\left(W_{x} \geq 103\right)$ & 0.0680 \\
\hline 5 & H14:Non-sharing of information Vs History of CDI & 83 & 88 & $P\left(W_{x} \geq 83\right)$ & 0.6019 \\
\hline 6 & H15:Non-sharing of information Vs Imperfect ADI & 102 & 69 & $P\left(W_{x} \geq 102\right)$ & 0.0807 \\
\hline \multicolumn{6}{|c|}{ Distributor } \\
\hline 7 & H16:Non-sharing of information Vs Periodic CDI & 119 & 52 & $P\left(W_{x} \geq 119\right)$ & 0.0009 \\
\hline 8 & H17:Non-sharing of information Vs History of CDI & 113 & 58 & $P\left(W_{x} \geq 113\right)$ & 0.0028 \\
\hline 9 & H18:Non-sharing of information Vs Imperfect ADI & 126 & 45 & $P\left(W_{x} \geq 126\right)$ & 0.0000 \\
\hline \multicolumn{6}{|c|}{$\begin{array}{ll}\text { Factory } \\
\end{array}$} \\
\hline 10 & H19:Non-sharing of information Vs Periodic CDI & 108 & 63 & $P\left(W_{x} \geq 108\right)$ & 0.0252 \\
\hline 11 & H20:Non-sharing of information Vs History of CDI & 120 & 51 & $P\left(W_{x} \geq 120\right)$ & 0.0006 \\
\hline 12 & H21:Non-sharing of information Vs Imperfect ADI & 126 & 45 & $P\left(W_{x} \geq 126\right)$ & 0.0000 \\
\hline
\end{tabular}

Table 7

Test for the best type of information sharing at upstream stages

\begin{tabular}{|c|c|c|c|c|c|}
\hline \multirow{2}{*}{$\begin{array}{c}\text { Sl. } \\
\text { No. }\end{array}$} & \multirow{2}{*}{ Hypothesis } & \multicolumn{4}{|c|}{ Wilcoxon Parameters } \\
\hline & & $W_{x}$ & $W_{y}$ & & $p$ \\
\hline \multicolumn{6}{|c|}{ Distributor } \\
\hline 1 & H22:Periodic CDI Vs History of CDI & 96 & 95 & $P\left(W_{x} \geq 96\right)$ & 0.1933 \\
\hline 2 & H23:Periodic CDI Vs Imperfect ADI & 116 & 55 & $P\left(W_{x} \geq 116\right)$ & 0.0028 \\
\hline 3 & H24:History of CDI Vs Imperfect ADI & 105 & 66 & $P\left(W_{x} \geq 105\right)$ & 0.0470 \\
\hline \multicolumn{6}{|c|}{ Factory } \\
\hline 4 & H25:Periodic CDI Vs History of CDI & 95 & 76 & $P\left(W_{x} \geq 95\right)$ & 0.2181 \\
\hline 5 & H26:Periodic CDI Vs Imperfect ADI & 115 & 56 & $P\left(W_{x} \geq 115\right)$ & 0.0039 \\
\hline 6 & H27:History of CDI Vs Imperfect ADI & 119 & 52 & $P\left(W_{x} \geq 119\right)$ & 0.0009 \\
\hline
\end{tabular}

\subsection{Impact of information sharing on inventory}

Impact of information sharing on total inventory of the supply chain is analysed by Wilcoxon-MannWhitney test and the results are tabulated in Table 8. The results show that the impact of imperfect ADI sharing is significant and it is concluded that the inventory of supply chain under this information sharing is less than the other types. But, a generalized conclusion could not be arrived at, when the stage-wise inventories of the different settings are tested. This may be due to the behaviour of safeharbour strategy of each stage member in the supply chain (Nienhaus et al., 2006). In safe-harbour strategy, a human being orders more than the required.

The hypotheses tested are as follows:

Hypothesis-H28: Total inventory of supply chain under non-sharing of information and under periodic CDI sharing are equal.

Hypothesis-H29: Total inventory of supply chain under non-sharing of information and under history of CDI sharing are equal.

Hypothesis-H30: Total inventory of supply chain under non-sharing of information and under imperfect ADI sharing are equal. 
Table 8

Test of total supply chain inventory: Details of Wilcoxon test parameters

\begin{tabular}{clcccc}
\hline S1. & \multirow{2}{*}{ Hypothesis } & \multicolumn{3}{c}{ Wilcoxon Parameters } \\
\cline { 3 - 5 } No. & & $W_{x}$ & $W_{y}$ & $p$ \\
\hline 1 & H28:Non-sharing of information Vs Periodic CDI & 93 & 78 & $P\left(W_{x} \geq 93\right)$ & 0.2729 \\
2 & H29:Non-sharing of information Vs History of CDI & 93 & 78 & $P\left(W_{x} \geq 93\right)$ & 0.2729 \\
3 & H30:Non-sharing of information Vs Imperfect ADI & 105 & 66 & $P\left(W_{x} \geq 105\right)$ & $\mathbf{0 . 0 4 7 0}$ \\
\hline
\end{tabular}

\section{Discussion}

To know the impact of CDI sharing in the performance of a supply chain, a four-stage serial supply chain having a small lead time (one period) operating in a non-backorders situation is analysed experimentally using supply chain role play game software package under non-sharing of information as well as different forms of CDI sharing. Statistical tests, namely, sign test and Wilcoxon test are conducted to know the impact of different forms of CDI on the following aspects of supply chain viz. presence of bullwhip effect, magnitude of variance of orders, and inventory.

The present study shows that there is a bullwhip effect in the supply chain under all forms of CDI sharing. Analysis of feedback of participants reveals that the reason for the presence of bullwhip is the behaviour of participants. Some of the participants said that they were helpless, and were in frustration when their suppliers could not supply the ordered quantity. This means that the participant might have used safe-harbour and/or panic strategy in their inventory management. This along with the delay in the availability of ordered material might have created an increase in the variability of orders from downstream to upstream stages. It may be noted that the effect of delay is minimised in the experiments by keeping the lead time to the smallest possible value.

Wilcoxon test reveals that magnitude of variance of orders is less in all forms of CDI sharing compared to non-sharing of information. Tests conducted to know the impact of CDI sharing on the variance of orders of each stage show that there is no clear evidence of impact of CDI sharing on downstream stages such as retailer and wholesaler but, there is a significant reduction in variance of orders at upstream stages such as distributor and factory. In the traditional supply chains (i.e., non-sharing information based supply chains), the variance of orders placed by stages (wholesaler, distributor, and factory) increases as we move from wholesaler to factory because the decisions are taken based on the orders placed by its downstream stage; its magnitude increase is less under all other information sharing cases. The imperfect ADI sharing is found to be the most effective than the other types.

At the end of each set of experiments, feedback is collected from the players and is explained below.

Many players participated keenly in all experiments and their feedback show that these experiments helped them to understand supply chain dynamics. During traditional (non-sharing of information) experiment, stage members were unable to predict their customer demand and were helpless when they could not meet the demand. Some were in frustration when their suppliers could not send the exact quantity ordered by them. Some of the retailers took utmost care to meet the customer demand during the experiments and some were unhappy when they could not meet it because of their suppliers. During the experiments with information sharing, they were comfortable to a certain extent than non-sharing of information case. During periodic CDI sharing experiments, some players pointed out the usefulness of periodic CDI sharing to the immediate stage of the retailer but not for far away stages due to lead time. However, the periodic CDI sharing is useful to take better decisions than without information sharing to a certain extent. They suggested that sharing the history of CDI with all members may be useful to upstream members. Some players reported that the experiment helped them to understand the importance of coordination in supply chain. All these information from feedback show the relevance of this experimental study, and the interest and involvement of the players during the experiments. 
The average value of each performance measure of supply chain under CDI information sharing has shown improvement compared to non-sharing information. The performance of supply chain is improved from periodic CDI to history of CDI, history of CDI to Imperfect ADI. The percentage reduction in magnitude of variance of orders placed by each stage under various settings is calculated and is tabulated in Table 9. (This is prepared for the cases where statistical test has shown significance.) The statistical test shows (see Table 5) that the players used periodic CDI sharing and history of CDI sharing in the same manner.

\section{Table 9}

Percentage reduction in the magnitude of variance of orders in CDI sharing compared to non-sharing information

\begin{tabular}{lrrrl}
\hline Information sharing type & \multicolumn{3}{c}{ Stage name } \\
\cline { 2 - 5 } & Retailer & Wholesaler & Distributor & Factory \\
\hline Periodic CDI & --- & --- & 51.34 & 35.63 \\
History of CDI & --- & --- & 43.23 & 48.60 \\
Imperfect ADI & --- & --- & 64.43 & 66.04 \\
\hline
\end{tabular}

The percentage of behavioural component present in the variance of orders can be quantified by comparing the results with a benchmark. For a supply chain, the benchmark results are possible by following a best or optimal inventory policy. Sometimes, a combination of information such as onhand inventory of various stages, inventory in the form of outstanding order of various stages and customer demand distribution sharing may further reduce the bullwhip effect. These are the areas to be explored further. Another avenue is finding the effect of sharing demand information in the form of forecast instead of demand distribution. The present study is having many managerial implications. It shows that behavioural aspect is one of the causes for bullwhip effect. Lack of CDI is also cause for BWE (Sterman 1989) and CDI sharing reduces the bullwhip effect as per the present study. Building a supply chain having customer demand distribution sharing is more beneficial than accurate CDI sharing. It also infers that the bullwhip effect cannot be eliminated completely but it can be controlled or reduced only.

\section{Conclusion}

Performance of a four-stage serial supply chain having a small lead time of one period operating under non-backorder situation is analysed experimentally to know the impact of Customer Demand Information (CDI) sharing. A supply chain role play game software package is developed to conduct the experiments. It is concluded that CDI sharing definitely has an impact on the performance of a supply chain. The performance of a supply chain increases with respect to the degree of customer demand information shared. Different forms of CDI sharing tested in this research are periodic CDI, history of CDI and CDI in the form of distribution. All these forms of information sharing found to have significant impact on the reduction of bullwhip effect compared to non-sharing information. The statistical analysis also confirms that sharing CDI in the form of distribution is the most effective one among the other forms studied and the upstream stages in the supply chain are the most benefited under CDI sharing. These studies also infer that bullwhip effect cannot be eliminated completely but it can be reduced or controlled. In the simulation study of inventory policy for impulse demand, Wadhwa et al., (2009) proposed that instead of using complicated tools to share accurate demand information to all stages, the mean demand information may improve the overall performance of a supply chain significantly. One of the conclusions of this experimental study is also in line with this concept. Statistical tests confirmed that there is no difference in stage-wise inventories under different supply chain settings in the present research. The safe-harbour strategy of each stage member in the supply chain may be the reason for the insignificant difference in the inventory at each stage in different supply chain settings. The conclusions of this study are limited to the assumptions, performance measures used, structure of supply chain and the parameters under which the experiments are conducted. The robustness of these results can be tested by conducting the experiments under different customer 
demand distributions as a further study. The impact of level or degree of CDI sharing on supply chain performance can also be studied using inventory policy for order decisions at each stage instead of using human being by simulation.

\section{Acknowledgement}

The authors acknowledge the sincere cooperation extended by the participants who participated in the experimental study.

\section{References}

Agrawal, S., Sengupta, R.N., \& Shankar, K. (2009). Impact of information sharing and lead time on bullwhip effect and on-hand inventory. European Journal of Operational Research, 192 (2), 576-593.

Anderson, E.D., Fine, C.H., \& Parker, G.G. (2000). Upstream volatility in the supply chain: The machine tool industry as a case study. POMS series in Technology and Operations Management, 9(3), 239-261.

Bendoly, E., Croson, R., Goncalves, P., \& Schultz, K. (2010). Bodies of knowledge for research in behavioural operations. Production and Operations Management, 19(4), 434-452.

Bhattacharya, R., \& Bandyopadhyay, S. (2011). A review of the causes of bullwhip effect in a supply chain. International Journal of Advanced Manufacturing Technology, 54(9-12), 1245-1261.

Bottani, E., Montanari, R., \& Volpi, A. (2010). The impact of RFID and EPC network on the bullwhip effect in the Italian FMCG supply chain. International Journal of Production Economics, 124(2), 426432.

Buchmeister, B., Pavlinjek, J., Palcic, I., \& Polajnar, A., (2008). Bullwhip effect problem in supply chains. Advances in Production Engineering \& Management, 3(1), 45-55.

Caloiero, G., Strozzi, F. and Comenges, J.Z., (2008). A supply chain as a series of filters or amplifiers of the bullwhip effect. International Journal of Production Economics, 114(2), 631-645.

Cantor, D.E., \& Katok, E. (2012). Production smoothing in a serial supply chain: a laboratory investigation. Transportation Research Part E, 48(4), 781-794.

Carter, C.R., Kaufmann, L., \& Michel, A. (2007). Behavioural supply management: A taxonomy of judgement and decision-making biases. International Journal of Physical Distribution \& Logistics Management, 37(8), 631-669.

Chan, H.K., \& Chan F.T.S. (2010). A review of coordination studies in the context of supply chain dynamics. International Journal of Production Research, 48(10), 2793-2819.

Chen F., Drezner Z., Ryan J.K., \& Simchi-Levi, D. (2000). Quantifying the bullwhip effect in a supply chain: The impact of forecasting, lead time and information. Management Science, 46(3), 436-443.

Chopra, S., \& Meindl, P. (2007). Supply chain management: Strategy, planning and operation. Prentice Hall of India: New Delhi.

Croson, R., \& Donohue, K. (2003). Impact of PoS data sharing on supply chain management: an experiment. Production and Operations Management, 12(1), 1-12.

Croson, R., \& Donohue, K. (2005a). Upstream versus downstream information and its impact on the bullwhip effect. System Dynamics Review, 21(3), 249-260.

Croson, R., Donohue, K., Katok, E., \& Sterman, J. (2014). Order stability in supply chains: coordination risk and the role of coordination stock. Production and Operations Management, 23(2), 176-196.

Croson, R., \& Donohue, K. (2006). Behavioural causes of the bullwhip effect and the observed value of inventory information. Management Science, 52(3), 323-336.

Dejonckheere, J., Disney, S.M., Lambrecht, M.R., \& Towill, D.R. (2003). Measuring and avoiding the bullwhip effect: A control theoretic approach. European Journal of Operational Research, 147(3), 567590.

Disney, S.M., \& Towill, D.R. (2003). The effect of vendor managed inventory (VMI) dynamics on the bullwhip effect in supply chains. International Journal of Production Economics, 85(2), 199-215.

Disney, S.M., \& Towill, D.R. (2006). A methodology for benchmarking replenishment-induced bullwhip. Supply Chain Management: An International, 11(2), 160-168.

Forrester, J. (1958). Industrial dynamics - A major breakthrough for decision makers. Harward Business Review, 36(4), 37-66. 
Ge, Y., Yang, J.B., Proudlove, N., \& Spring, M. (2004). System dynamics modeling for supply-chain management: A case study on supermarket chain in the UK. International Transactions in Operational Research, 11(5), 495-509.

Kok, T.D., Janssen, F., Doremalen, J.V., Wachen, E.V., Clerkx, M., \& Peeters, W. (2005). Philips electronics synchronizes its supply chain to end the bullwhip effect. Interfaces, 35(1), 37-48.

Lee, H.L, Padmanabhan, V., \& Whang, S. (1997). The bullwhip effect in supply chains. Sloan Management Review, 38(3), 93-102.

Metters, R., (1997). Quantifying the bullwhip effect in supply chains. Journal of Operations Management, 15(2), 89-100.

Nienhaus, J., Ziegenbein, A., \& Schoensleben, P. (2006). How human behavioural amplifies the bullwhip effect. A study based on the beer distribution game online. Production Planning and Control, 17(6), 547-557.

O’donnell, T., Maguire, L., Mcivor, R., \& Humphreys, P. (2006). Minimizing the bullwhip effect in a supply chain using genetic algorithms. International Journal of Production Research, 44(8), 1523-1543.

Ouyang Y., \& Li X., (2010). The bullwhip effect in supply chain networks. European Journal of Operational Research, 201(3), 799-810.

Paik, S. K., \& Bagchi, P. K. (2007). Understanding the causes of the bullwhip effect in a supply chain. International Journal of Retail \& Distribution Management, 35(4), 308-324.

Pillai, V.M., \& Pamulety, T.C. (2013). Impact of backorder on supply chain performance: an experimental study. Proceedings of International conference on Manufacturing Modelling, Management and Control, Saint Petersburg, Russia, June 19-21, 1967- 1972.

Siegel, S., \& Castellan, N.J. (1988). Nonparametric statistics for the behavioural sciences. McGraw Hill international editions: Singapore.

Simchi-Levi, D., Kaminsky, P., Simchi-Levi, E., \& Shankar, R. (2008). Designing and Managing the Supply Chain - concepts, strategies and case studies. Tata McGraw-Hill, New York.

Steckel, J.H., Gupta, S., \& Banerji, A. (2004). Supply chain decision making: will shorter cycle times and shared point-of-sale information necessarily help? Management Science, 50(4), 458-464.

Sterman, J.D. (1989). Modeling managerial behaviour: Misperceptions of feedback in a dynamic decision making experiment. Management Science, 35(3), 321-339.

Sterman, J.D. (2009). The Beer Game", Available from: http://web.mit.edu/jsterman/www/SDG/beergame.html [Accessed 1 May 2009].

Sucky, E. (2009). The bullwhip effect in supply chains - An overestimated problem? International Journal of Production Economics, 118(1), 311-322.

Tan, T., Gullu, R., \& Erkip, N. (2007). Modelling imperfect advance demand information and analysis of optimal inventory policies. European Journal of Operational Research, 177(2), 897-923.

Taylor, D.H. (2000). Demand amplification: has it got us beat? International Journal of Physical Distribution \& Logistics Management, 30(6), 515-533.

Terwiesch, C., Ren, Z.J., Ho, T.H., \& Cohen, M.A. (2005). An empirical analysis of forecast sharing in the semiconductor equipment supply chain. Management Science, 51(2), 208-220.

Tokar, T. (2010). Behavioural research in logistics and supply chain management. The International Journal of Logistics Management, 21(1), 89-103.

Wadhwa, S., Bibhushan, \& Chan, F. T. (2009). Inventory performance of some supply chain inventory policies under impulse demands. International Journal of Production Research, 47(12), 3307-3332.

Wang, X., Liu, Z., Zheng, C., \& Quan, C. (2008). The impact of Lead time on bullwhip effect in supply chain. IEEE transactions, 3, 93-97.

Wright, D., \& Yuan, X. (2008). Mitigating the bullwhip effect by ordering policies and forecasting methods. International Journal of Production Economics, 113(2), 587-597.

Wu, D.Y., \& Katok, E. (2006). Learning, communication and bullwhip effect. Journal of Operations Management, 24(6), 839-850.

Zymelman, M. (1965). A stabilization policy for the cotton textile cycle. Management Science, 11(5), 572580. 